\title{
Late responses as aids to diagnosis in peripheral neuropathy
}

\author{
T LACHMAN, B T SHAHANI, AND R R YOUNG
}

From the Clinical Neurophysiological Laboratories, Massachusetts General Hospital and Harvard Medical School, Boston, Massachusetts

SUMMARY The usefulness of performing late response studies for the detection of peripheral nerve dysfunction has been demonstrated. It has been shown that significant prolongation of the minimal latencies of the $\mathrm{H}$ reflex and the $\mathrm{F}$ response is present at a time when conventional methods of motor and sensory conduction do not show an abnormality in individual patients. Abnormalities of late responses have been shown to occur in a variety of peripheral neuropathies with "axonal" as well as "segmental demyelination" type of underlying pathology.

Clinical signs and symptoms of peripheral nerve dysfunction can frequently be correlated with abnormalities of conduction in groups of large motor and sensory nerve fibres ${ }^{1-10}$ particularly if results from populations of patients (for example mean motor nerve conduction velocity) are contrasted with data from large numbers of normal subjects. When using standard techniques to study individual patients, however, one often finds the values for maximal motor and sensory conduction velocity to be within the normal range in a number of patients who have obvious clinical features of polyneuropathy. In order to improve the diagnostic yield of electrophysiological studies in individual patients with various peripheral neuropathies, we have studied the efficacy of two easily elicitable late responses, the F-response, which can be recorded from almost any skeletal muscle, and the H-reflex, which can be easily recorded from the soleus muscle. These two simple, reproducible physiolcgical responses were studied to evaluate conduction along the course of the whole "final common pathway", from the motoneurone to the terminal axon, as well as (in the case of the H-reflex) to gain some information regarding

Presented at the 26th International Congress of Physiological Sciences Satellite Meeting of Motor System: Neurophysiology and Muscle Mechanisms, Bombay, 1974.

Address for reprint requests: Dr BT Shahani, Massachusetts General Hospital, Fruit Street, Boston 02114, Mass., USA.

Accepted 24 September 1979 the function of large diameter group Ia afferent fibres supplying the muscle spindle.

\section{Material and methods}

F-response latencies were recorded from the abductor pollicis brevis muscle (APB) in one hundred normal control subjects who did not have any clinical evidence of central or peripheral nervous system disorders. H-reflex latencies were recorded from the soleus muscle in seventy-five normal control subjects. The criteria used to differentiate between the H-reflex and the $F$ response are listed in Table 1 . Similar techniques, outlined below, were applied to 50 patients with various neuropathies (Table 4).

All subjects were examined in the supine posi:ion in a room where the temperature varied from 27 to $30^{\circ} \mathrm{C}$. Surface temperature recordings were made from the mid-forearm when the F-response latency was determined, and ranged from 31 to $34^{\circ} \mathrm{C}$. When the $\mathrm{H}$-reflex latency was recorded, the surface temperature of the calf ranged from 30 to $32.5^{\circ} \mathrm{C}$.

The F-response was recorded from the abductor pollicis brevis muscle (FAPB) using surface disc electrodes (TECA 6030). The active electrode was taped over the motor point and the reference electrode was placed over the proximal phalanx of the thumb. A bipolar stimulating electrode was placed over the median nerve at the wrist (TECA 6030-1), and a TE-4 electromyograph was used for stimulation and 
Table 1 Criteria for differentiation between $H$-reflex and $F$-response

\begin{tabular}{|c|c|c|}
\hline & $H$-reftex & F-response \\
\hline Type of response & $\begin{array}{l}\text { Monosynaptic } \\
\text { reflex }\end{array}$ & $\begin{array}{l}\text { "Recurrent discharge", } \\
\text { not a reflex }\end{array}$ \\
\hline Afferent arc & Ia afferents & $\alpha$ motor fibres \\
\hline Efferent arc & $\alpha$ motor fibres & $\alpha$ motor fibres \\
\hline Distribution & $\begin{array}{l}\text { Soleus-gastrocnemius } \\
\text { in adults }\end{array}$ & Many skeletal muscles \\
\hline $\begin{array}{l}\text { Stimulus Threshold } \\
\text { (relative to that } \\
\text { required to evoke } \\
\text { the } M \text { or direct } \\
\text { motor response) }\end{array}$ & Lower & Higher \\
\hline $\begin{array}{l}\text { Appearance and } \\
\text { persistence of } \\
\text { response }\end{array}$ & $\begin{array}{l}\text { Constant at low } \\
\text { rates of stimulation }\end{array}$ & Variable \\
\hline $\begin{array}{l}\text { Amplitude (compared } \\
\text { to the direct motor } \\
\text { response) }\end{array}$ & Larger & Smaller \\
\hline $\begin{array}{l}\text { Effect of a single } \\
\text { supramaximal stimulus } \\
\text { for motor fibres }\end{array}$ & Absent & Present \\
\hline $\begin{array}{l}\text { Single motor units } \\
\text { activated in the } M \\
\text { and late response }\end{array}$ & Different & Same \\
\hline $\begin{array}{l}\text { Single motor unit } \\
\text { jitter }\end{array}$ & $>\mathrm{F}>\mathrm{M}$ & $>\mathrm{M}$ but $<\mathrm{H}$ \\
\hline
\end{tabular}

Table 2 Normal values for F-response (recorded from abductor pollicis brevis)

\begin{tabular}{ll}
\hline Number of subjects & 100 \\
Responses measured (one or both sides) & 124 \\
Age range & $12-81$ years (mean 39.8) \\
Height range & $142-188 \mathrm{~cm}$ (mean 170) \\
Mean latency & $26.0 \mathrm{~ms}$ (S.D. 1.9) \\
Range of latency & 22.3 to $30.0 \mathrm{~ms}$ \\
Correlation latency vs height & $\mathrm{r}=0.67$ \\
$\begin{array}{l}\text { Correlation latency vs age } \\
\text { Maximal difference in latency between }\end{array}$ & $\mathrm{r}=0.21$ \\
two sides & $2.0 \mathrm{~ms}$ \\
\hline
\end{tabular}

recording. The stimulus frequency was one every two seconds and the pulse duration was $0.1 \mathrm{~ms}$. Supramaximal shocks were delivered to the median nerve by adjusting the voltage to be $20 \%$ more than that required to produce maximal direct motor (M) responses. Multiple pictures were taken since the amplitude and configuration of F-responses recorded from the surface are characteristically variable from moment to

Table 3 Normal values for $\boldsymbol{H}$-reflex (recorded from soleus)

\begin{tabular}{ll}
\hline Number of subjects & 75 \\
Responses measured (one or both sides) & 123 \\
Age range & $15-81$ years (mean 37.2) \\
Height range & $150-196 \mathrm{~cm}$ (mean 170) \\
Mean latency & $29.4 \mathrm{~ms}(\mathrm{~S} . \mathrm{D} .2 .1)$ \\
Range of latency & 25.0 to $34.7 \mathrm{~ms}$ \\
Correlation latency vs height & $\mathrm{r}=0.66$ \\
Correlation latency vs age & $\mathrm{r}=0.19$ \\
Maximal difference in latency between & \\
two sides & $2.2 \mathrm{~ms}$ \\
\hline
\end{tabular}

moment. Latencies were uniformly measured to the beginning of the first deflection from the baseline. Ten F-responses were recorded and the minimal latency of these was used to provide information regarding the fastest conducting motor nerve fibres.

For determination of H-reflex latencies, the active surface electrode was placed over the medial bulge of soleus muscle, below the level of the lower margin of the medial gastrocnemius muscle. The reference electrode was placed distally over the Achilles tendon. The tibial nerve was located within the popliteal fossa by adjusting the position of the stimulating electrode and monitoring the amplitude of the direct motor response until the site with the lowest threshold was identified. The polarity of the bipolar stimulating electrode was then reversed so that the cathode was proximal. The stimulus frequency was one per two seconds, and the pulse duration ranged from $0 \cdot 1$ to $1 \mathrm{~ms}$. The voltage was increased until the maximal H-reflex amplitude was obtained. Multiple pictures were taken, and the response with the shortest latency to the beginning of the first deflection from the baseline was measured. The ages and heights of each subject were recorded.

\section{Results}

Values for F-response and H-reflex latencies (late response latencies, LRL) in normal subjects are listed in Tables 2 and 3. The mean F-response latency in APB was $26.0 \mathrm{~ms}$., with a range of 22.3 to $30.0 \mathrm{~ms}$. The mean $\mathrm{H}$-reflex latency was $29.4 \mathrm{~ms}$., with a range of 25.0 to $34.7 \mathrm{~ms}$. As one might expect, F-response and H-reflex latencies were well correlated with height, the coefficient of correlation for the F-response latency and height beingg $r=0.67$, and for the H-reflex latency and height, $r=0.66$. Linear regression lines were determined for $F$ response and H-reflex latencies as functions of height and these correlations are illustrated in Figures 1 and 2 . We found a poor correlation between the F-response or H-reflex latencies and age $(r=0.21$ and $r=0.19$ respectively). When age and height were used to predict the F-response and H-reflex latencies, the coefficient of multiple correlation increased to $r=0.72$ for each late response. A multiple regression equation was calculated for F-latency as a dependent variable using height and age; FAPB latency $(\mathrm{ms})=3.62$ +0.04 age $(\mathrm{yr})+0.12$ height $(\mathrm{cm}) \pm 1.3$ (standard error). The multiple regression equation using the H-reflex latency as a variable dependent on 
Table 4 Late responses in neuropathy

\begin{tabular}{|c|c|c|c|c|c|}
\hline $\begin{array}{l}\text { Type of } \\
\text { neuropathy }\end{array}$ & $\begin{array}{l}\text { Number } \\
\text { examined }\end{array}$ & $\begin{array}{l}\text { Abnormal late response } \\
\text { normal NCS }\end{array}$ & $\begin{array}{l}\text { Normal late response } \\
\text { abnormal NCS }\end{array}$ & $\begin{array}{l}\text { Abnormal late response } \\
\text { abnormal NCS }\end{array}$ & $\begin{array}{l}\text { Normal late response } \\
\text { normal NCS }\end{array}$ \\
\hline Uraemic & 7 & 3 & 0 & 3 & 1 \\
\hline Alcoholic-nutritional & 6 & 1 & 0 & 2 & 3 \\
\hline Porphyric & 1 & 0 & 0 & 0 & 1 \\
\hline $\begin{array}{l}\text { Diabetic and Uraemic } \\
\text { Charcot-Marie-Tooth } \\
\text { Chronic Demyelinating }\end{array}$ & 1 & 0 & 0 & 1 & 0 \\
\hline Neuropathy & 10 & 0 & 0 & 10 & 0 \\
\hline $\begin{array}{l}\text { Refsum's Disease } \\
\text { Guillain Barré }\end{array}$ & 1 & 0 & 0 & 1 & 0 \\
\hline Syndrome & 11 & 2 & 1 & 8 & 0 \\
\hline Total & 50 & 9 & 2 & 34 & 5 \\
\hline
\end{tabular}

height and age was calculated: H-reflex latency $(\mathrm{ms})=2.74+0.05$ age $(\mathrm{yr})+0.14$ height $(\mathrm{cm})$ \pm 1.4 (standard error). In $95 \%$ of the normal population, the measured F-response and $\mathrm{H}$ reflex latencies will fall within two standard errors $(2.6 \mathrm{~ms}$. for $\mathrm{F}, 2.8 \mathrm{~ms}$. for $\mathrm{H})$ of the predicted values using the above formulae.

A summary of the data obtained from fifty patients with clinical and laboratory evidence of neuropathy due to a clearcut etiology is shown in Table 4. In patients who did not have ankle jerks, an H-reflex could not be obtained from the soleus muscle; the minimal latency late response recorded in this instance was an F-response.

Of seven patients with uraemic neuropathy, three had abnormally prolonged LRL though their routine nerve conduction studies (NCS) were normal.* Three of thirteen patients with

*Motor conduction velocities and distal latencies for at least the median, ulner, peroneal, and tibial nerves on one side, and distal orthodromic conduction times for median and ulnar nerve sensory fibers.

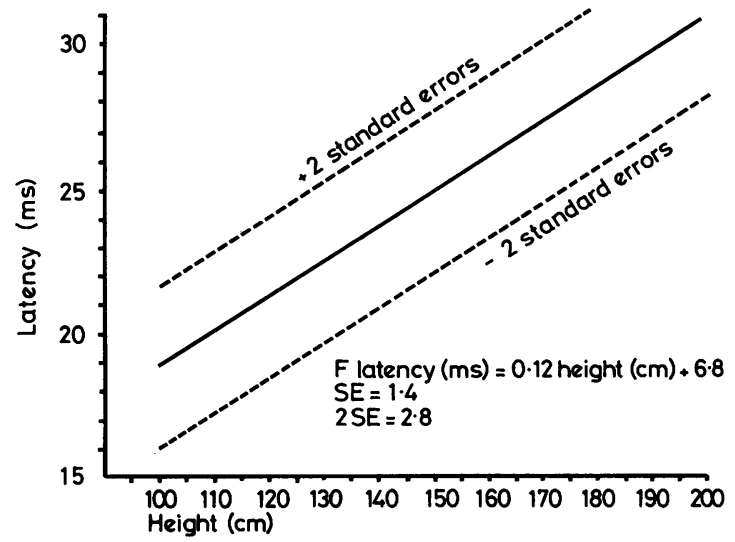

Fig 1 Relationship of the height $(\mathrm{cm})$ of normal subjects to the minimal latency of the F-response. diabetic neuropathy also had abnormally prolonged LRL and normal routine NCS. One of these patients had a normal LRL in the abductor pollicis brevis and soleus muscles; the only abnormality in the peripheral nerve conduction studies was an isolated femoral neuropathy. One of six patients with alcoholic-nutritional neuropathy had prolonged LRL and normal routine NCS. Each of the ten patients with CharcotMarie-Tooth disease and one patient with Refsum's disease had moderate to marked slowing of coduction in routine NCS plus markedly prolonged LRL (fig 3). Eleven patients with Guillain-Barré idiopathic polyneuritis were examined within two weeks of onset of the disease. Two had prolonged LRL at a time when their cerebrospinal fluid protein and routine NCS were still within normal limits. When these tesis were repeated one to two weeks later, peripheral NCS as well as cerebrospinal fluid protein had become abnormal. Initially in one additional patient with only mild clinical weakness, a prolonged distal latency in the peroneal nerve from

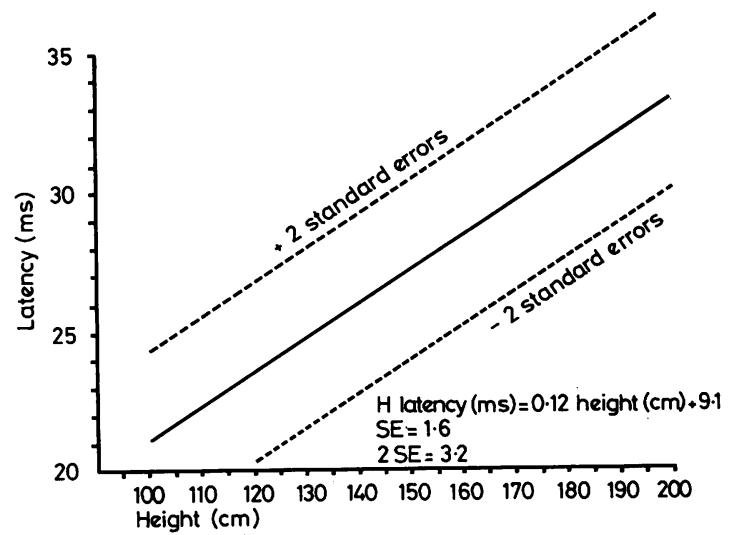

Fig 2 Relationship of the height $(\mathrm{cm})$ of normal subjects to the minimal latency of the H-reflex. 
ankle to the extensor digitorum brevis muscle was the only abnormality. Re-examination two weeks later showed a prolonged F-response latency from abductor pollicis brevis, as well as abnormalities of conduction in additional peripheral nerves.

In our group of fifty patients with assorted neuropathies, $18 \%$ had abnormal LRL at a time when routine NCS were normal.

\section{Discussion}

The F-response was thought by Magladery \& McDougal, ${ }^{11}$ who originally described it in man, to be a polysynaptic reflex evoked by stimulation of slow conducting afferent fibres. More recent evidence challenges this concept and it is now generally agreed that the F-response as recorded by EMG is due to a centrifugal discharge from individual motor neurones which is initiated by an antidromic volley in their axons. ${ }^{12-14}$ By recording from single motor units, Thorne ${ }^{14}$ found that direct activation of a motor axon by the electrical stimulus is necessary to elicit an F-response thereby supporting the view that the F-response recorded from the surface represents recurrent discharges of several antidromically activated motor neurones. This has subsequently been confirmed by Schiller and Stalberg ${ }^{15}$ and others.

The H-reflex, originally described by Hoffman in 1918, arises following stimulation of Ia afferent fibers in a mixed nerve. In adults it is easily recorded from the soleus muscle following stimulation of the tibial nerve; it can also be found in muscles that maintain posture, but is not ordinarily elicitable in relaxed distal muscles. It can be found in multiple muscles of infants less than one year of age, and in adults with upper motor neurone lesions, particularly when the cervical cord and lower brainstem are involved. ${ }^{11} 1416$

In recent years, many investigators have used F-response and H-reflex studies to evaluate function of the peripheral nervous system, ${ }^{17-35}$ but the methods have often ben unsatisfactory because they are based on several assumptions. The first assumption made by these investigators is that the first single motor unit activated in the minimal latency F-response is also the first one in the M-response. However, in our preliminary studies on single motor units, we have found this to be an exception rather than the rule. Further careful studies will have to be performed before definite conclusions can be made regarding the behavior of single motor units in the $F$ and $M$ responses. The second assumption made by these investigators is that the distance measured from a fixed vertebral process (for example C-7 in the neck) to the point of stimulus in the proximal segment of arm or leg reflects an accurate conduction distance from the activated spinal motoneuron to the point of stimulus. When one considers the inaccuracies of distance measurements inherent in the conventional methods of determining maximal motor conduction velocity in distal segments where points of stimulation are fairly well defined, the degree of inaccuracy in estimating length of the proximal segment from the "unknown" motoneuron must be enormous. The third assumption made by those measuring F-response conduction velocity is that it takes precisely 1 ms for the recurrent discharge to occur at the motoneuron. This value-cturnaround time"has never been recorded in human subjects and is based on studies in the spinal cord preparation of experimental animals. ${ }^{36}$ Since methods (requiring multiple supramaximal stimuli at different sites) used for the measurement of F-response conduction velocity, in addition to being time consuming and uncomfortable to patients, introduce several errors, we feel it is unnecessary to convert accurate primary data (that is latency measurements) to conduction velocity.

At the present time, the only accurate method for evaluating conduction in proximal segments is to measure latencies of late responses in proximal muscles or to determine LRL in distal muscles and compare them with conventionally recorded maximal motor conduction velocity in distal segments of peripheral nerves supplying the same muscles. Further studies are being performed to develop techniques which can measure conduction accurately in different segments of the nerves. Until such time as more reliable techniques for measurement for conduction velocity in the proximal segment of nerves are developed, previous studies must be interpreted with caution.

Although their latencies are similar, the Fresponse should be differentiated from the H-reflex (Table 1) since the pathways producing each of these two responses are not the same. ${ }^{37}$ Conduction in the axon of an alpha motor neuron is tested by F-response latency, while $\mathbf{H}$ reflex latency gives information about activity in large afferent (Ia) as well as efferent fibres.

Wager and Buerger ${ }^{35}$ recently described a method for the measurement of "sensory conduction velocity" based on the assumption that 
they had evoked H-reflexes in intrinsic foot muscles after stimulation of tibial and peroneal nerves at the level of ankle and knee. However, in normal adult subjects, H-reflexes can usually be elicited only in the soleus-gastrocnemius muscle (provided the ankle jerk is present); a single electrical stimulus almost never evokes an H-reflex in intrinsic hand or foot muscles without voluntary background activity. The late responses recorded by these authors were Fresponses rather than $\mathrm{H}$-reflexes and therefore do not give information about conduction in the afferent or sensory fibres as suggested. Since it cannot be determined whether the F-response produced by stimulation at two different sites on the peripheral nerve represents activity of the same motoneurons, this method for measurement of conduction velocity is inadequate for the reasons outlined above.

There appears to be a direct relationship between the minimal latency of late responses and the height (fig 2 and 3) and length of the extremity. ${ }^{21}$ We recorded height in the present study to make our methods as simple and reproducible as possible as well as to avoid errors which are inherent in the measurement of length of various segments of nerves in human subjects. The present study has clearly shown that there is an excellent relationship between height and minimal latency of late responses.

We have observed a common pattern of transition from H-reflex to $F$-wave in the soleus muscle in a variety of patients with neuropathy. There are similarities between our findings and those of Mayer and Mawdsley ${ }^{28}$ whose patients received spinal anaesthesia. The initial change, early in neuropathy, is a decreased amplitude and prolonged latency of $\mathrm{H}$-reflexes. As the neuropathy progresses, the usual triphasic appearance of the H-reflex may be replaced by an asynchronous response at a time when the direct muscle response has a normal shape (fig 4). Finally, the H-reflex may disappear altogether; in which instance an F-wave is recorded with prolonged latency.

The presence of an abnormal late response latency in $18 \%$ of patients in whom peripheral motor and sensory conduction was within normal limits illustrates the significance of performing these simple physiological studies. It is interesting to note that the abnormalities of late responses are present in a large variety of peripheral neuropathies, including those where the primary pathology affects the axon as well as those where the myelin sheath is primarily involved. There are several explanations that might account for this finding. 1: a longer pathway is tested, so that borderline abnormalities measured by the standard technique are amplified, 2: the neuropathy may affect the proximal nerve segments that are not measured by routine methods, 3: the "utilisation time" of the anterior horn cells may be prolonged by the neuropathy, and 4: late response latencies have a narrower normal range than routine motor conduction velocities. ${ }^{21}$

Late response latencies are simple to determine, are reproducible, and can be performed in every electromyography laboratory since there is no need for specialized equipment such as averagers. In fact, whenever nerve conduction velocities are obtained, this extra information is easily recorded and measured because supramaximal stimulation evokes not only the direct muscle response, but also an F-response, which can be obtained at the same time without additional discomfort to the patient. Although there is evidence that changes in persistence and amplitude of F-responses may eventually prove to be useful for quantitative analysis of central nervous system function, ${ }^{38}$ we recommend that, at the present time, these studies be used only to evaluate conduction in alpha motor axons.

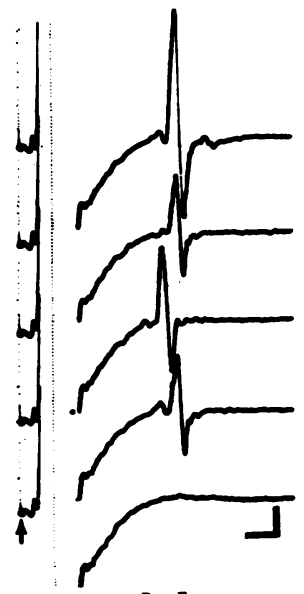

Fig 3
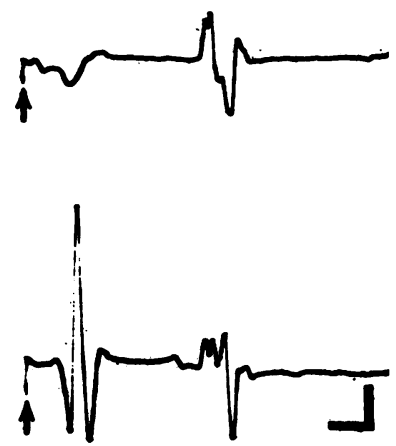

Fig 4
Fig 3 F-response recorded from the abductor pollicis brevis of a patient with Refsum's disease (Latency 36-40 msec.). Calibration: $10 \mathrm{msec}$. and $200 \mu$ volts.

Fig 4 H-reflex with a prolonged latency (42 min.) in a patient with uremic neuropathy. Stimulus intensity (submaximal for M-response) is increased between $A$ and $B$. Note the relatively asynchronous $H$-reflex with normal triphasic $M$ response (B). Calibration: $10 \mathrm{msec}$. and $200 \mu$ volts. 
On the basis of our findings, we feel that late response latency measurements and comparison with normograms such as illustrated in Figures 2 and 4 should become part of standard nerve conduction studies in every clinical electromyography laboratory. There is no longer any reason to doubt that application of these new techniques leads to earlier detection and better documentation of peripheral nerve pathology in individual patients.

\section{References}

1 Bastron JA, Lambert EH. The clinical value of electromyography and electric stimulation of nerves. Med Clin North Am 1960; 44:1025-36.

2 Cerra D, Johnson EW. Motor nerve conduction velocity in "idiopathic" polyneuritis. Arch Phys Med Rehab 1961; 42:159-63.

3 Dyck PJ, Lambert EH, Mulder DW. CharcotMarie-Tooth Disease: Nerve conduction and clinical studies of a large kinship. Neurol 1963; 13:1-11.

4 Gilliatt RW, Willison RG. Peripheral nerve conduction in diabetic neuropathy. J Neurol Neurosurg Psych 1962; 25:11-18.

5 Gilliatt RW. Nerve conduction in human and experimental neuropathies. Proc $R$ Soc Med 1966; 59:989-93.

6 Henriksen JD. Conduction velocity of motor nerves in normal subjects and in patients with neuromuscular disorders. Thesis, U Minnesota.

7 Kaeser HE. Nerve conduction velocity measurements. In: Vinken PJ, Bruyn GW, eds. Handbook of Clinical Neurology. New York: American Elsevier Pub Co, 1970: vol 7 116-96.

8 Mavor $\mathrm{H}$, Libman I. Motor nerve conduction velocity measurement as a diagnostic tool. Neurology 1962; 12:733-44.

9 Mawdsley C, Mayer RF. Nerve conduction in alcoholic polyneuropathy. Brain 1965; 88:335-56.

10 Mulder DW, Lambert EH, Bastron JA, Sprague RG. The neuropathies associated with diabetes mellitus: A clinical and electromyographic study of 103 unselected diabetic patients. Neurology 1961; 11:275-84.

11 Magladery JW, McDougal DB. Electrophysiological studies of nerve and reflex activity in normal man. I. Identification of certain reflexes in the electromyogram and the conduction velocity of peripheral nerve fibres. Bull Johns Hopkins 1950; 86:265-90.

12 McLeod JG, Wray SH. An experimental study of the F-wave in the baboon. J Neurol Neurosurg Psych 1966; 29:196-200.

13 Mayer RF, Feldman RG. Observations on the nature of the F-wave in man. Neurology 1967; 17:147-56.
14 Thorne J. Central responses to electrical activation of the peripheral nerves supplying the intrinsic hand muscles. J Neurol Neurosurg Psych 1965; 28:482-95.

15 Schiller HH, Stalberg E. F-response studied with single fibre EMG in normal subjects and spastic patients. J Neurol Neurosurg Psych 1978; 41: $45-53$.

16 Thomas JE, Lambert EH. Ulnar nerve conduction velocity and $H$-reflex in infants and children. J Appl Physiol 1960; 15:1-9.

17 Ackil AA, Shahani BT, Young RR. Sural conduction studies and late responses in children undergoing hemodialysis. Arch Phys Med Rehab 1978; 59:62.

18 Adams RD, Shahani BT, Young RR. A severe pansensory familial neuropathy. Trans $A m$ Neurol Assoc 1973; 98:67-9.

19 Albizzati MG, Bassi S, Passerini D, Crespi V. F-wave velocity in motor neurone disease. Acta Neurol Scand 1976; 54:269-77.

20 Braddom RI, Johnson EW. Standardisation of H-reflex and diagnostic use in S-1 radiculopathy. Arch Phys Med Rehab 1974; 55:161-6.

21 Conrad B, Aschoff JC, Fischler M. Der diagnostische Wert der F-wellen-Latenz. J Neurol 1975; 210:151-9.

22 Eisen A, Schomer D, Melmed C. The application of $\mathrm{F}$-wave measurements in the differentiation of proximal and distal upper limb entrapments. Neurology (Minneap) 1977; 27:662-8.

23 Kimura J. F-wave velocity in the central segment of the median and ulnar nerves. A study in normal subjects and in patients with CharcotMarie-Tooth Disease. Neurology 1974; 24:539-46.

24 Kimura J, Butzer JF. F-wave conduction velocity in Guillain-Barre syndrome. Arch Neurol 1975; 32:524-9.

25 King D, Ashby P. Conduction velocity in the proximal segments of a motor nerve in the Guillain-Barre syndrome. J Neurol Neurosurg Psych 1976; 39:538-44.

26 Lachman T, Shahani BT, Young RR. Late responses as diagnostic aids in Landry-GuillainBarre syndrome. Electroencephalogr Neurophysiol 1977; 43:147.

27 Lefebre-D'Amour M, Shahani BT, Young RR, Bird KT. Importance of studying sural conduction and late responses in the evaluation of alcoholic subjects. Neurology 1976; 26:368.

28 Mayer RF, Mawdsley C. Studies in man and cat of the significance of the H-reflex. J Neurol Neurosurg Psych 1965; 28:201-9.

29 Panayiotopoulos CP, Scarpalezos S, Nastas PE. F-wave studies in the deep peroneal nerve. Part 1: Control subjects. J Neurol Sci 1977; 31:319-29.

30 Panayiotopoulos CP, Scarpalezos S. F-wave studies in the deep peroneal nerve. Part 2: 1, Chronic renal failure; 2 , Limb-girdle muscular dystrophy. J Neurol Sci 1977; 31:331-41. 
31 Panayiotopoulos CP. F-wave conduction velocity in the proximal segment of the deep peroneal nerve: Charcot-Marie-Tooth Disease and dystrophica myotonica. Muscle and Nerve 1978; 1:37-44.

32 Panayiotopoulos CP, Scarpalezos S, Nastas PE. Sensory (Ia) and F-wave conduction velocity in the proximal segment of the tibial nerve. Muscle and Nerve 1978; 1:181-9.

33 Shahani BT, Young RR, Lachman T. Late responses as aids to diagnosis in peripheral neuropathy. J Postgrad Med 1975; $21: 7$.

34 Wager EE Jr, Buerger AA. H-reflex latency and sensory conduction in normal and diabetic subjects. Arch Phys Med Rehab 1974; 55:126-219.

35 Wager EE Jr, Buerger AA. A linear relationship between the H-reflex latency and sensory conduction velocity in neuropathy. Neurology 1974; 24:711-5.

36 Renshaw B. Influence of discharge of motoneurons upon excitation of neighbouring motoneurons. J Neurophys 1941; 4:167-83.

37 Shahani BT, Young RR. Effect of vibration on the F-response. In: Shahani M, ed. The Motor System: Neurophysiology and Muscle Mechanisms Sec IV, Chap 6. Amsterdam: Elsevier Sci Pub Co, 1976: 185-95.

38 Fisher MA, Shahani BT, Young RR. Assessing segmental excitability after acute rostral lesions: I. The F-response. Neurology (Minneap) 1977; 28:1265-71. 